\title{
Carers and Professionals' Perspectives on Foster Care Outcomes: The Role of Contact
}

\section{Paulo Delgado, João M. S. Carvalho, Vânia S. Pinto \& Joana Oliveira}

To cite this article: Paulo Delgado, João M. S. Carvalho, Vânia S. Pinto \& Joana Oliveira (2017) Carers and Professionals' Perspectives on Foster Care Outcomes: The Role of Contact, Journal of Social Service Research, 43:5, 533-546, DOI: 10.1080/01488376.2017.1340392

To link to this article: https://doi.org/10.1080/01488376.2017.1340392

\section{曲 Published online: 25 Jul 2017.}

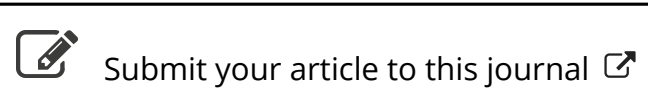

Џll Article views: 260

View Crossmark data ${ }^{\top}$ 


\title{
Carers and Professionals' Perspectives on Foster Care Outcomes: The Role of Contact
}

\author{
Paulo Delgado ${ }^{\mathrm{a}, \mathrm{b}}$, João M. S. Carvalho ${ }^{\mathrm{a}, \mathrm{c}, \mathrm{d}}$, Vânia S. Pinto ${ }^{\mathrm{a}, \mathrm{e}}$, and Joana Oliveira ${ }^{\mathrm{a}}$ \\ ${ }^{a}$ inED, Escola Superior de Educação do Politécnico do Porto, Porto, Portugal; ${ }^{\mathrm{b}} \mathrm{CIEC}$, Universidade do Minho, Braga, Portugal; ${ }^{\mathrm{C} C I C S} . \mathrm{NOVA}$, \\ Universidade do Minho, Braga, Portugal; ' dUNICES, Instituto Universitário da Maia, Maia, Portugal; ${ }^{\mathrm{e}} \mathrm{REES}$ Centre, Department of Education, \\ University of Oxford, Oxford, UK
}

\begin{abstract}
This study investigates the association between the contact of children or young people in care with their family, and the foster care placement evaluation (positive or negative) in Portugal. According to the perspectives of foster carers and service professionals' perceptions regarding children and young people's reactions, during and after the visits, are measured. Utilizing a quantitative approach, two fostering services teams and 140 foster carers completed questionnaires, which had 212 children in common. Results indicated that despite the importance of continued contact, especially for children and their parents, it was not determined to be essential to long-term placement. On one hand, there was the perception that a high percentage of children expressed positive reactions during and after the visit, while on the other hand, this didn't influence the perception of placement success. This study also showed significant differences between foster carers' and the professionals' perceptions on several dimensions of foster care, especially the children's reactions during visits. These differences need to be further analyzed in future research and the outcomes used to help improve contact management.
\end{abstract}

\section{KEYWORDS}

Contact with biological family; children's rights; children's wellbeing; foster care

\section{Children and Young People's Contact in Foster Care}

Children and young people in residential or foster care have the right to maintain contact with their family, similar to separation or divorce processes, according to item no. 3 of article 9 of the Convention on the Rights of the Child (United Nations, 1989). Contact with the parents, despite the associated difficulties and the challenges, is an essential right from both a legal and ethical points of view. This contact is central to the child's or young person's individual care plan. It may also be central to reunification with their family, with subsequent influence on their wellbeing and their future relationships (McWey \& Mullis, 2004). Biological family contact is considered important for children and young people as it is believed to contribute to their adaptation to placement. Therefore, recognizing the importance of this contact for adaptation to placement, it needs to be closely monitored and supported by social services at the educational and emotional levels (McWey \& Mullis, 2004).
Authors such as Déprez and Wendland (2015), reviewed the literature on contact with the biological family while the child or young person is in residential care. These authors stressed the need for more research related to the maintenance of contact between the child and their family, and its quality as well as whether the continued contact for children and young people may be beneficial or not. Furthermore, Salas, Fuentes, Bernedo, and García (2016) after analyzing in detail the contact arrangements in foster care and its quality, stressed the need to tailor contact according to each case and reported the need to invest on intervention strategies to improve the quality of contact visits. Therefore, it is important to analyze contact and its quality in further detail in the Portuguese context and to reflect on the implications for practice.

In Portugal, similar to other countries, placement in foster care differs from that of residential care, mainly because children and young people are integrated in a family environment. This type of placement allows for

CONTACT Paulo Delgado pdelgado@ese.ipp.pt Escola Superior de Educação do Politécnico do Porto, R. Dr. Roberto Frias, 602, 4200-465, Porto, Portugal. ○ 2017 Taylor \& Francis Group, LLC 
the establishment of a privileged relationship with the carer. These connected relationships require an equilibrium between foster carers and biological families working together to assist the child or young person in care.

The carer is not a substitute for biological parents, "but an original figure, who creates with the child unprecedented bonds and must conquer their place against the exclusive image of 'one father, one mother, one family' "(Théry, 1999, p. 131). In fact, it is expected that the carers provide an environment characterized by stability, security, attention, and empathy, in order to reconcile tangible areas with intangible ones, such as pain and loss management (Aldgate, Maluccio, \& Reeves, 1989). Cairns (2002) adds to these carer attributes a friendly dedication, a positive or benevolent attitude (friendliness) distinct from friendship, a "mix of love and joy, combined with a passionate dedication to his or her well-being" (p. 73). David (2000) speaks about providing security, the meeting of needs, and the experience of daily life, guided by individual respect, and allowing the child or young person in care to learn of the existence of limits in a family system, a different set of experiences from those which the child may have been removed. Beek and Schofield (2004a) refer to physical and emotional readiness, the sensitivity to understand, respect, and reflect on children's thoughts and feelings, as well as the ability to respond to their manifested needs, being typical of a reflective carer.

Neil and Howe (2004) report two conditions, which are not sufficient in themselves, but can help to achieve positive results: compatibility between the child and carers, and the capacity of the carers to manage external factors that can collide with foster care including contact with the biological family.

Contact is more successful, has better outcomes, and is more easily arranged when the foster carers accept its potential value, and when they do not intend to take the place of the biological family in the child's life (Sen \& Broadhurst, 2011). When contact is characterized by cooperation rather than conflict, the child can maintain a sense of belonging to both the foster carers' and their biological family (Neil, Beek, \& Schofield, 2003). Nevertheless, the general principle of investment in contact can be rejected if it is harmful to the child's best interests. This raises the need for regular, careful assessment of the outcomes of contact (Barber \& Delfabbro, 2004). This follow-up requires experience, skills, and time on behalf of those undertaking it, and should keep in mind: the child's stage of development and age, the purpose of the placement, the parental capacity of the family member with whom the contact takes place, the way this family member relates with the child, the caregiving skills of the foster carer, and the child's own opinion (Atwool, 2013; Selwyn, 2004; Sen \& Broadhurst, 2011). The planning of contact needs to be flexible and adaptable to naturally occurring changes in the needs and feelings of all actors involved, namely in relation to type, frequency, duration of contact, and more specifically to visits, location. In order to ensure better outcomes, the contact should be supervised, and visits should be monitored before, during and after, by contacting the different stakeholders involved.

In situations of maltreatment, some of which are particularly serious, the likelihood of placement success increases if certain people are forbidden to have contact with the child. Therefore, it is important to avoid a situation where the contact visits become a moment of remembrance, or, in the absence of supervision, a moment where the trauma can be repeated (Howe \& Steele, 2004; Wilson \& Sinclair, 2004). Children and young people's safety and protection stands as the priority, along with the promotion of attachment to the foster carers. The possibility of some kind of contact with the biological family is typically only evaluated later (Browne \& Moloney, 2002; Cairns, 2002; Howe, 1995; Howe, Brandon, Hinings, \& Schofield, 1999).

In Portugal, few studies have been carried out in the area of foster care. Therefore, this work aims to study the characterization of contact in the Portuguese context; to evaluate the effect it has on the wellbeing of the child or young person from professionals' and carers' perspectives; to identify the difficulties that these actors have in maintaining said contact; and to determine if the contact influences the overall assessment by professionals and carers of the foster care situation, in terms of helping or hindering the child's development.

\section{Literature Review}

The growing interest in contact in foster care results mainly from the impact that it has on the development of the child, the foster care system, placement stability, and the possibility of placement breakdowns (Osborn 
\& Delfabbro, 2009; Ward, Munro, \& Dearden, 2006). Most of the research and reflection on theoretical frameworks, contexts, and foster care practices takes place in Anglo-Saxon countries. However, there is an emergent and growing interest in Iberian countries, particularly in Spain.

This section highlights the findings of studies from the geographical areas referred to previously (AngloSaxon countries and Spain), in order to analyze contact patterns, models, and outcomes. Prevalence was given to studies that focused on the contact process from the point of view of children and young people, foster carers, biological families, and fostering services teams. The selection criteria included: studies that analyzed emotional and behavioral reactions and studies that looked into the impact of contact on stability, permanence, reunification, and satisfaction with the contact experience. To summarize, this section will focus on how contact is actually made, what are its main aims, and what outcomes the contact leads to. Certain studies combined all these aims, while others were focused only on a specific field. Furthermore, the findings from these studies do not always agree, revealing the need to keep debating, reflecting and investigating, with the aim of constructing accurate knowledge on contact in foster care.

The frequency of contact visits may be affected by difficulties experienced by the biological family, particularly in terms of money and transport. Triseliotis (2010) highlights among several factors, poor monitoring, negative attitudes of the people involved in the placement, and long distances between the biological family's home and where the child is placed as being difficulties with the contact process. These can be classified as informal barriers, and can also include the discouragement of the contact and the reinforcement of uncomfortable circumstances in which the child and their family must have contact by foster carers (Sinclair, Gibbs, \& Wilson, 2004). These obstacles can be tackled with greater commitment, closer placements, easier access to transport for biological parents, and choice of more accessible and functional contact venues (Cleaver, 2000).

Vanschoonlandt, Vanderfaeillie, Van Holen, De Maeyer, and Andries (2012) compared contact in foster care (with no family ties) with in kinship care (in the extended family) in Belgium, and came to the conclusion that despite the frequency of mother-child contact being similar in both type of placements, foster care achieved better outcomes in the areas related to parents' attitudes. For example, a greater number of mothers accepted the placement and permanency of the child or young person in foster care, and were more likely to keep a good relationship with the carers. A good relationship between the biological father and the carer was also more common in this type of placement. For these authors, the findings stressed that a shared culture and similar background, which is normally the case for kinship care, do not necessarily contribute to better cooperation between parents and foster carers. The quality of cooperation depends more on limits and the setting of roles and responsibilities for both parties, which is more common in foster care, and will facilitate intervention when problems arise.

In kinship care, the management of contacts between foster carers, children and young people in care, and their parents is, according to Hunt, Waterhouse, and Lutman (2008), one of the most stressful aspects of a professionals' role. The organization of contact requires special attention from the professional since it can be affected by family disputes. According to Coakley (2013), children and young people in care face a higher risk of having worse psychosocial outcomes when their parents are absent or when they are not involved in the placement process, than if their parents are involved. They are at risk of having negative outcomes such as poverty, school dropout, and addictive behavior such as the use of alcohol, tobacco and illicit drugs.

They are also more likely to enter the juvenile justice system or to be arrested in the future. Coakley (2013) analyzed 60 foster care cases in the United States and concluded that when biological parents were involved, their children had shorter placements and were more likely to achieve reunification or to be placed in their extended family. Similarly, Mcwey, Acock, and Porter (2010) found (again in the United States) that contact with parents was a protective factor against internalization problems, such as depression or anxiety, and externalization problems, such as conduct disorder. Cantos, Gries, and Slis (1997) (once again in the United States), reached the same conclusion, correlating fewer behavioral problems with more frequent contact visits. This correlation, however, depended on the type of behavior under analysis and the child's degree of adjustment to the foster carer. The same authors also ascertained that the longer 
children or young people are looked after, the greater the number of movements within the protection system, and this lowers the probability of contact.

Correlation between the existence of contact and the likelihood of reunification is questioned by research (Barber \& Delfabbro, 2004; Cantos et al., 1997; Wilson \& Sinclair, 2004). The contacts may reflect the will of the children and young people, their parents, and the decisions of the professionals according to the child's individual care plan, but not be a cause of reunification per se. Subsequently, there are far more children and young people that maintain contact with their biological families, than those who end up returning to said family. As Delfabbro, Barber, and Cooper (2002) found in Australia, "although a certain level of contact is needed to achieve reunification, the relationship appears to be correlational rather than causative" (p. 37). Children who have the most frequent contact with their families, and are better adjusted, are less likely to stay in care. Other factors can impact contact frequency, such as difficulties the child might have (e.g. hyperactivity).

Sinclair (2005) stressed that according to professionals the most common reason for contact is not to "allow the return home, but simply to keep the relationship and respect the wishes of parents and children" (p. 90). Schofield, Beek, Sargent, and Thoburn (2000) in a longitudinal study about long term permanency in foster care based in England, mentioned that the absence of contact with members of the biological family, especially when the child wished to have contact, could be problematic and potentially harmful. Delfabbro et al. (2002) mentioned two other reasons for maintaining contact, besides reunification: longterm attachment between children and their families and enhancing the psychological wellbeing of children and young people in care.

The most significant aspect of contact, beyond its existence and frequency, it is the quality of the experience, and the fact that it proves appropriate for all the parties involved, especially for the child or young person in care (Schofield \& Stevenson, 2009). In short, contact cannot be restricted in its aims to the possibility of reunification. It should have broader objectives, which will require specific work with the biological family, starting immediately after the separation, and which will facilitate its implementation (Sinclair, 2005).
Nevertheless, it is also not uncommon to find reports by children and young people where the contact visits with biological parents can be emotionally distressing and lead to the manifestation of emotional and behavioral problems (Beek \& Schofield, 2004b; Biheal, 2006; Moyers, Farmer, \& Lipscombe, 2006; Sinclair, Baker, Wilson, \& Gibbs, 2005; Sinclair et al., 2004; Wilson \& Sinclair, 2004). For example, Neil et al. (2003), in their British study, found that at least a third of children in foster care seemed to experience stress associated with contact with their biological parents. Authors such as Moyers et al. (2006), in England, found that the absence of contact is preferable to problematic contact for children and young people, since it will allow for the removal of traumatic relations and the possibility of establishing new attachments with caring adults.

Padbury and Frost (2002) (also in England), concluded that, based on their study, children should have the opportunity to keep in touch with supportive friends. For this reason, professionals need to encourage and facilitate these relationships, which can be particularly difficult when the placement is distant from the previous place of residence, or when it leads to a school change. Ofsted (2009) reaffirmed this evidence in the English context, emphasizing the importance of supporting the maintenance of children's contact with key members of their social network, whether family, friends, "foster care siblings," or foster carers from previous placements. Other studies emphasized the importance of contact with biological siblings (Heptinstall, Bhopal, \& Brannen, 2001; McAuley, 1996; Whiting \& Lee, 2003). Research has also recognized the importance of giving a voice to children and young people in care, and to valuing, whenever possible, their opinion and thereby fulfilling the right of participation, which has been introduced into law, but still needs to be addressed in practice (Gilligan, 2000; Moyers et al., 2006; Sinclair, Wilson, \& Gibbs, 2001).

A study conducted in Scotland by Sen and McCormack (2011) focused on the experiences of 22 professionals in the field of contact management during short term placements, identifying strengths and difficulties in practice. The authors ascertained that foster carers have a small amount of involvement in contact, but that involvement hinders the establishment of a positive interaction with the biological family. They also found that foster carers' expectations regarding 
their level of involvement in contact management are likely to be strongly influenced by the fostering services teams' attitudes at the recruitment stage. For this reason, the involvement of biological families in the training of foster carers, as well as the participation of experienced foster carers can be a way to tackle some prejudices and ensure that foster carers have a positive impact on contact with the biological family. As implications for practice, the authors suggested that professionals need to consider foster carers as partners in the planning and organization of contact. Foster carers will provide better support if they understand its purpose and if they feel that they are part of the fostering team. This involvement can be achieved if foster carers are included in planning meetings along with other professionals, if they have ongoing training and if they receive the relevant information about the child in their care.

In the Iberian context, there are only a few studies related to contact. Palacios and Jiménez (2007) conducted a study in Andalusia, Spain, about contact in foster care, using a sample of 218 children and young people in care and their foster carers. The study showed that about $70 \%$ of the children and young people in the study did not receive parental contact visits and approximately $45 \%$ had no contact with their mother. The findings also highlighted that approximately $30 \%$ of foster carers evaluated the impact of the contact visits on children and young people negatively. The data collected in our study, based in Portugal, revealed a lower percentage of children and young people without contact, $33 \%$ according to professionals and $40.1 \%$ according to foster carers. The evaluation of the impact of contact on children and young people is nevertheless similar, as $39.4 \%$ of the carers thought that the reactions of the children and young people during the visit were negative, while $31.1 \%$ thought that the reactions after the visit were negative.

Salas, Fuentes, Bernedo, García, and Camacho (2009), conducted a study in the province of Málaga, Spain, and concluded that contact between foster carers and biological families there is infrequent. In approximately $60 \%$ of cases there is no contact of any kind, the established system of visits is not followed, and professionals evaluated the contact visits negatively. Analysis of the relationship between how well the system of visits was followed and the reasons that led to the child's removal revealed that most of the mothers that follow the system of visits have been separated from their children for reasons of neglect, while those who had been separated due to more severe problems, such as drug addiction, did not follow the system.

Delgado, López, Carvalho, and Del Valle (2015) analyzed the adaptation of children and young people to foster care in Portugal and Spain, comparing various dimensions of their life at the present moment and at the moment they entered the placement. Foster carers' perception of the impact of the relationship with the biological family on, and the consequences of contact for, children and young people's adaptation to the placement was not positive. In the Spanish case, a difficult relationship between children and young people in care and foster carers' children also contributed negatively towards the adaptation of children and young people in care. All the other evaluated dimensions were associated with positive adaptation of children and young people, regardless of the country, in such areas as: their integration and relationship with foster carers, social relationships, physical health, psychological wellbeing, behavioral positive outcomes, and school attainments.

\section{Methodology}

\section{Sample}

A sample of 221 children and young people in foster care were examined in the district of Porto, which accounted for $59.1 \%$ of all children and young people in foster care in Portugal (Instituto da Segurança Social, 2014). 200 of these children and young people were looked after by foster carers recruited by the public Institute of Social Security of Porto, the government institution that runs the child protection system, while 21 were looked after by carers recruited by the organization "Mundos de Vida", a private institution that has an agreement with the state and therefore is authorized to provide foster care. This data was gathered by asking the two fostering services teams to complete questionnaires about all the children and young people in their care. These children and young people came from 161 biological families and were looked after by 141 different foster carers. The study included a total of 97 girls (43.9\% of the total) and 124 boys (56.1\% of the total), with a mean age of 15.14 years $(\mathrm{SD}=4.78)$.

A total of 140 foster carers responsible for fostering these children and young people also completed 
questionnaires, which covered 217 children and young people. These children and young people belonged to 159 different biological families and included a total of 95 girls (43.8\% of the total) and 122 boys (56.2\% of the total) with a mean age of 15.36 years $(S D=4.76)$.

\section{Instruments}

One questionnaire was completed by members of the fostering services teams (social workers, social educators, psychologists) who supervise the whole process of foster care and give support to children, biological families, and foster carers. This questionnaire covered the full sample of 221 children and young people in foster care, and asked questions about: the age and sex of the child or young person; the duration of the placement; professionals' frequency of contact with foster carers (with possible answers selected from: at least once every two weeks, at least once a month, at least once every three months, at least once every six months, at least once a year, never); evaluation of foster care regarding its outcomes (with possible answers selected from: successful, some positive results, some problems, serious problems); the attitudes of the parents towards the foster carers at the beginning of the placement and currently (with possible answers selected from: opposition, cooperation, absence, ambiguous, other); characterization of the contact between the child or young person and their family [variables: existence of contact (yes or no); time when the contact ended; reasons for the end of contact (death of the parents, opposition to foster care intervention, disinterest of parents, opposition of foster family, etc.); children's reactions to the end of contact (happiness/wellbeing, anger/fear, sadness/distress, indifference/apathy, etc.); characterization of contact between the child or young person and their family; difficulties regarding contact occurrence (distance, location, travel costs, etc.); and professionals' monitoring of the placement (non-existent, insufficient, sufficient, good, very good)].

A similar questionnaire was used with the foster carers, as it was intended to compare the perspectives of foster carers and professionals. This questionnaire sought information about: the age and sex of the child or young person; the duration of the placement; the frequency of contact by the fostering services teams; an evaluation of foster care regarding its outcomes; the attitude of the parents towards the foster carers at the beginning of the placement and currently; a characterization of the contact between the child or young person and their family; any difficulties with contact occurrence; and professionals' monitoring of the placement.

Data was treated confidentially, maintaining the anonymity of participants, and with the approval of the ethics boards of all institutions involved.

\section{Procedure}

The two questionnaires were developed by the authors with the participation and approval of the two institutions involved. The foster carers completed their questionnaires in the presence of one member of the research team, in order to ensure a high number of responses. All questionnaires, including those completed by the fostering services teams, were completed between October 2013 and March 2014.

The data was analyzed using descriptive and inferential statistical analysis within the software IBMSPSS. It was found 212 children and young people were present in both samples, allowing for comparison between the perspectives of professionals and foster carers. All results discussed in this work are based on the 212 children and young people covered by both questionnaires.

\section{Findings}

\section{Characterization of Contact with Biological Family}

Most children and young people in foster care maintained contact with their family, nevertheless the percentage of children and young people in the study that did not have any contact with their biological family was still relatively high (28.8\%).

Analysis of professionals' and foster carers' responses regarding contact between children and young people and their families (Table 1), it was showed that there is some disagreement between these

Table 1. Occurrence of contact according to professionals and foster carers.

\begin{tabular}{clccc}
\hline & & \multicolumn{3}{c}{ Foster carers questionnaire } \\
\cline { 3 - 5 } & & $\begin{array}{c}\text { With } \\
\text { contact }\end{array}$ & $\begin{array}{c}\text { Without } \\
\text { contact }\end{array}$ & Total \\
\hline $\begin{array}{c}\text { Professionals } \\
\text { questionnaire }\end{array}$ & With contact & 118 & 24 & 142 \\
& Without contact & 9 & 61 & 70 \\
& Total & 127 & 85 & 212 \\
\hline
\end{tabular}


two groups about the frequency of contact., Professionals reported that 142 children and young people maintained contact ( $67 \%$ of the total), while foster carers reported that only 127 children and young people maintained contact (59.9\% of the total). There was agreement regarding the continuation or cessation of contact between professionals and foster carers in 179 cases ( $84.5 \%$ of the total), but in 24 cases $(11.3 \%$ of the total) professionals reported that there was contact while foster carers reported that there was not, and in 9 cases (4.2\% of the total), the opposite was reported. It can be noted that foster carers reported that there were fewer children and young people in contact with their biological family than the professionals from the fostering services teams,. There is a strong statistically significant association between the answers to this question and the role they have in the system (professional or foster carer $)\left(\chi^{2}=96.313 ; \mathrm{V}=.674\right.$; $p<.001)$. It should be noted that professionals are more informed about a child's individual care plan, while foster carers are more aware of what happens in their everyday life.

This data may indicate that there is a lack of communication between the different participants involved in the foster care process namely, professionals from the fostering services teams, foster carers, and the biological families. These findings may be explained by the possibility that the biological family is authorized to contact the child or young person but the contact may not occur, or, the possibility that the biological family is not allowed to have contact with the child and yet somehow establishes contact.

A more detailed analysis of the likelihood of contact between the child or young person in care and their biological family based on the variables age of the child or young person and duration of the current placement reveals several statistically significant trends, all of which exist in both the data collected from both the foster carers and the professionals. Children and young people who have contact with their family were on average younger than those who did not have contact, with statistically significant differences both in the data collected from professionals $(\mathrm{t}=4.466, p<.001)$ and from foster carers $(\mathrm{t}=$ 3.584, $p<.001)$. Children and young people who have contact with their family were also in foster care for less time (Table 2) and this effect was once again statistically significant in both samples: professionals $(\mathrm{t}=6.218, p<.001)$ and foster carers $(\mathrm{t}=4,171$;
Table 2. Age and duration of the current placement according to existence or not of contact (years).

\begin{tabular}{cccccc}
\hline & \multicolumn{2}{c}{ With contact } & & \multicolumn{2}{c}{ Without contact } \\
\cline { 2 - 5 } \cline { 5 - 5 } & $\begin{array}{c}\text { Age } \\
\text { mean }\end{array}$ & $\begin{array}{c}\text { Duration of the } \\
\text { current placement }\end{array}$ & $\begin{array}{c}\text { Age } \\
\text { mean }\end{array}$ & $\begin{array}{c}\text { Duration of the } \\
\text { Current placement }\end{array}$ \\
\hline $\begin{array}{c}\text { Professionals } \\
\text { questionnaire }\end{array}$ & 14.07 & 7.45 & 16.93 & 12.17 \\
& 13.94 & 7.44 & 16.62 & 11.35 \\
\hline
\end{tabular}

$p<.001)$. From this it can be concluded that the longer the child or young person is in care, the greater the likelihood of losing contact with their family, which agrees with the conclusions drawn by Cantos et al. (1997).

As previously stated, of the 212 children and young people where it was possible to collect both professionals' and foster carers' perspectives, only about twothirds have contact with their biological family, 142 cases according to professionals and 127 according to foster carers. However, not all of these children and young people received visits from their families. Professionals reported that of the 142 children and young people still in contact with their family, 87 have visits and other forms of contact, while 50 have only visits, and 5 have only contact via phone and/or social networks, i.e. not face to face contact. Foster carers reported that of the 127 children and young people that have contact with their family, 75 receive visits and have other forms of contact, while 42 receive only visits, and 10 have contact that is not face to face. These non-face to face contacts happen mostly with the mother, father, siblings, uncles, grandparents, or other family members. Contact through social networks and text messages has a higher incidence of being between siblings.

To better understand the impact of contact between the child or young person and their family, it is important to describe the reactions of the child or young person during the contact visit. According to professionals, $92.3 \%$ of children and young people experienced happiness, wellbeing, contentment, satisfaction, or tranquility. Other reactions with lower percentages were indifference, apathy, passivity or disinterest, sadness or distress, and anger or fear (Figure 1).

Foster carers had a more pessimistic view than professionals, reporting that the number of children and young people who experienced happiness, wellbeing, contentment, satisfaction, or tranquility, represented only $60.6 \%$ of cases, and that more children expressed 


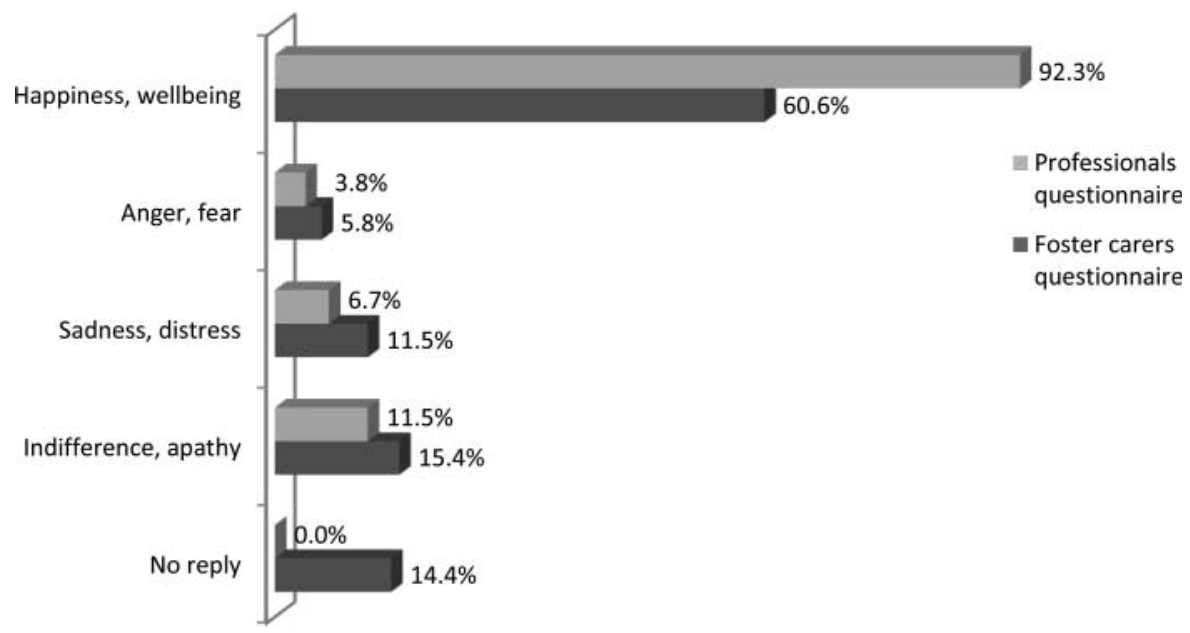

Figure 1. Children and young people's reactions during visits (multiple answer).

indifference, sadness or revolt. The perspectives of Foster carers' in this area are concordant with the data obtained by Neil et al. (2003) and Palacios and Jiménez (2007).

It should be noted that not all children and young people have their visits monitored by professionals or foster carers. These differences in perception are very relevant and may impact the assessments that stakeholders make regarding the whether or not to continue contact or even continue the placement.

Of the 129 replies where it is possible to compare professionals' and foster carers' perspectives regarding the children and young people's reactions during contact visits, there is only agreement in $50.4 \%$ of cases (Table 3). Although professionals are more optimistic compared when with foster carers in this area, it should be noted that they assessed 7 children as having reactions of sadness, distress, indifference or apathy, while foster carers reported that those same children or young people expressed reactions of happiness and wellbeing. Therefore, it should be stressed that the data points out a reasonable dissonance between professionals and foster carers, despite the trend for optimism amongst professionals regarding contact.

Professionals and foster carers were also asked about their perspectives on children and young people's reactions after visits (Figure 2). Professionals reported that in $80.2 \%$ of cases, reactions after the visits with the biological family were of happiness and wellbeing. Although this is a high percentage, it is lower than the percentage of reports of happiness and wellbeing during visits (92.3\%, Figure 1). Additionally, there is an increase of reports of indifference or apathy reactions, from $11.5 \%$ during visits to $20.8 \%$ after visits; of sadness or distress, from $6.7 \%$ during visits to $19.8 \%$ after visits; and anger or fear, from $3.8 \%$ during visits to $9.4 \%$ after visits.

Foster carers observed a somewhat different pattern, as they reported an increase in reactions of happiness and wellbeing from $60.6 \%$ during visits to $68.9 \%$ after visits, of indifference or apathy from $15.4 \%$ during visits to $19.8 \%$ after visits, and of anger or fear from $5.8 \%$ during to $7.5 \%$ after visits. Only regarding reactions of sadness or distress did they report a decrease after visits compared to during visits, from $11.5 \%$ to $11.3 \%$ respectively.

Table 3. Perspectives about the reactions during visits (multiple answer).

\begin{tabular}{|c|c|c|c|c|c|c|c|}
\hline & & \multicolumn{5}{|c|}{ Foster carers questionnaire } & \multirow[b]{2}{*}{ Total } \\
\hline & & Happiness, wellbeing & Anger, fear & Sadness, distress & Indifference, apathy & No reply & \\
\hline \multirow{5}{*}{$\begin{array}{l}\text { Professionals } \\
\text { questionnaire }\end{array}$} & Happiness, wellbeing & 59 & 5 & 11 & 13 & 15 & 103 \\
\hline & Anger, fear & 0 & 1 & 0 & 3 & 1 & 5 \\
\hline & Sadness, distress & 1 & 0 & 1 & 3 & 2 & 7 \\
\hline & Indifference, apathy & 6 & 1 & 1 & 4 & 2 & 14 \\
\hline & Total & 66 & 7 & 13 & 23 & 20 & 129 \\
\hline
\end{tabular}




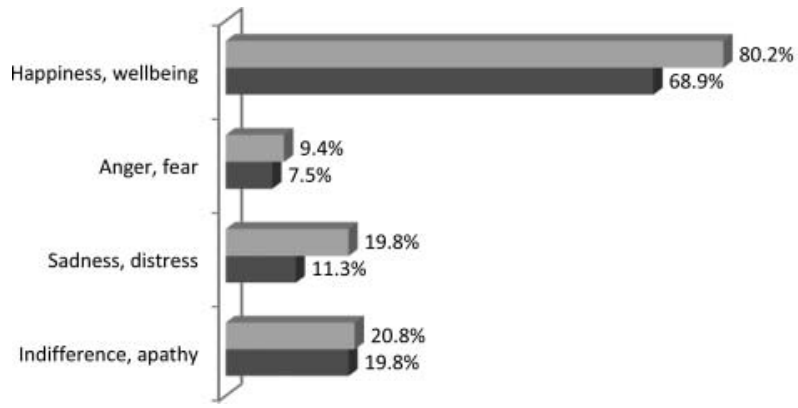

= Professionals questionnaire

Eoster carers questionnaire

Figure 2. Children and young people's reactions after visits (multiple answer).

By way of explanation it may be possible that professionals consider that children and young people are happier with their parents, while foster carers think that they are happier with them. These findings raise new research questions: how effectively do professionals and foster carers evaluate children and young people's reactions to family visits? Are professionals provided with the time and resources to perform this evaluation well? And, do foster carers prefer children and young people to remain integrated in their family instead of being reunified with their biological family thus biasing their evaluations?

It is also important to understand the difficulties in carrying out contact visits identified by foster carers and professionals in their responses to the questionnaires. In $50.5 \%$ of cases professionals identified no difficulties in carrying out contact visits, while foster carers identified fewer cases (38.1\% of cases) with no associated difficulty (Figure 3).

The main difficulties reported by professionals and foster carers were: travel costs $(32.4 \%$ and $25.7 \%$ of cases, respectively), biological family not following agreements (24.8\% and $27.6 \%$ of cases, respectively), distance between the biological family's home and the child or young person's placement $(24.8 \%$ and $17.1 \%$ of cases, respectively), and children and young people's unwillingness $(10.5 \%$ and $11.4 \%$ of cases, respectively).

It should be pointed out that there is a an agreements rate of $74.3 \%$ between professionals and foster carers with respect to their reports of difficulty in carrying out contact between children and young people

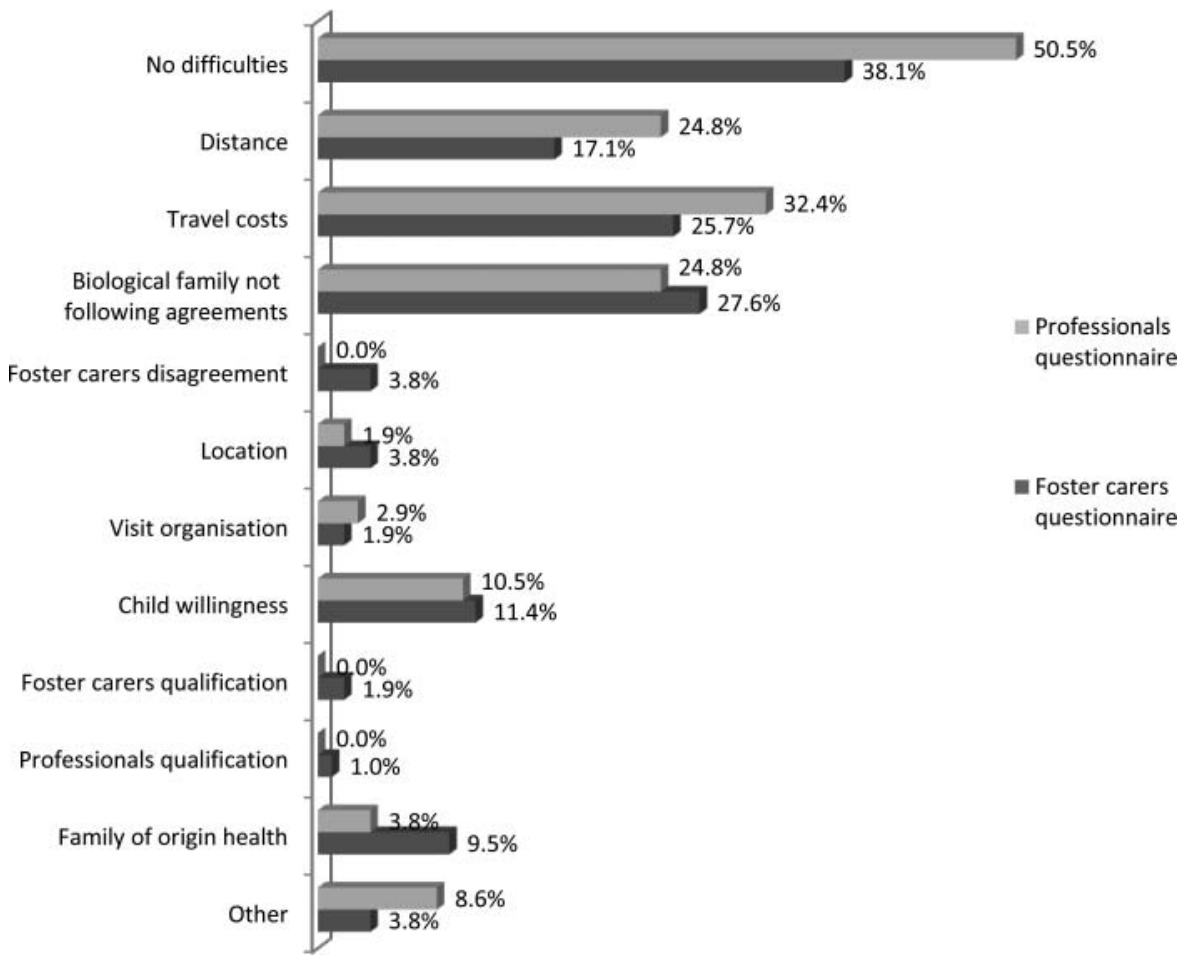

Figure 3. Difficulties identified in carrying out contact visits (multiple answer). 
in care and their families. By analyzing each of these dimensions, it can be seen that professionals were more focused on difficulties such as travel costs, the distance between the biological family's home and the child or young person's placement, visit planning and organization, and other reasons (which includes relational difficulties between biological family, foster carers, and children and young people) when compared with foster carers. On the other hand, foster carers were more focused on biological families not following agreements, children and young people's unwillingness to participate in visits, health problems in the biological family, foster carers' disagreement with the visits, visit location, and foster carers' and professionals' preparation and training. Based on these responses, it can be argued that professionals tend to be more focused on logistical difficulties, whereas foster carers tend to identify more difficulties associated with relational and emotional problems.

\section{Evaluation of Foster Care Outcomes}

In terms of foster care outcomes, which were measured via professionals' and foster carers' perceptions on children and young people's wellbeing, it can be noted that the majority classified the outcomes as successful, $67 \%$ and $59 \%$ of cases respectively (Figure 4). Surprisingly, there was agreement between professionals and foster carers about the outcome of foster care in only $51.1 \%$ of the cases. Furthermore, foster carers appeared to have a more pessimistic attitude than professionals in 52 cases, and more optimistic attitude in 40 cases, with the difference between the distributions of professionals and foster carers being statistically significant (K-S-2 $=6.95 ; p<.001)$. It appears therefore, that professionals did not point out as many problems with foster case as the carers themselves.

Another important takeaway from our data relates to the fact that the evaluation of the outcome of foster care appears to be independent of whether or not there is contact between children and young people and their family, regardless of who evaluated it, professionals (K-S-2 $=.349 ; p=1$ ) or foster carers (K-S$2=.55 ; p=.923)$. Based on this, it can be concluded that the existence or non-existence of contact between children and young people and their family has no statistically significant influence on the evaluation of foster care outcomes, i.e. in the view of both professionals and foster carers, contact with the biological family did not appear to influence the success or failure of foster care. Perhaps the placement of a child or young person into foster care for an extended period breeds the idea within the minds of the professionals and foster carers involved that contact with the biological family is no longer relevant to placement success. This could be explained by the fact that long term placement is associated with the assumption that the conditions for family reunification have not been created, and therefore one of the main aims for the child's individual care plan was not accomplished. Ultimately, the view that contact between children and young people in care and their families does not have an impact on the outcomes of placement is in agreement with the perspective of Sinclair (2005): maintaining the relationship between, and the presence of the biological family in the life and identity of the child is what legitimates contact, contact should not be treated as a means of improving the outcomes of the placement, or of enhancing the likelihood of reunification, but as a process unto itself.

\section{Discussion}

The perspectives of professionals from fostering services teams and of foster carers is that contact between children and young people and their family does not significantly influence the outcome of foster care. Placement success was measured based on professionals' and foster carers' perceptions of children and young people's wellbeing, to which contact was not

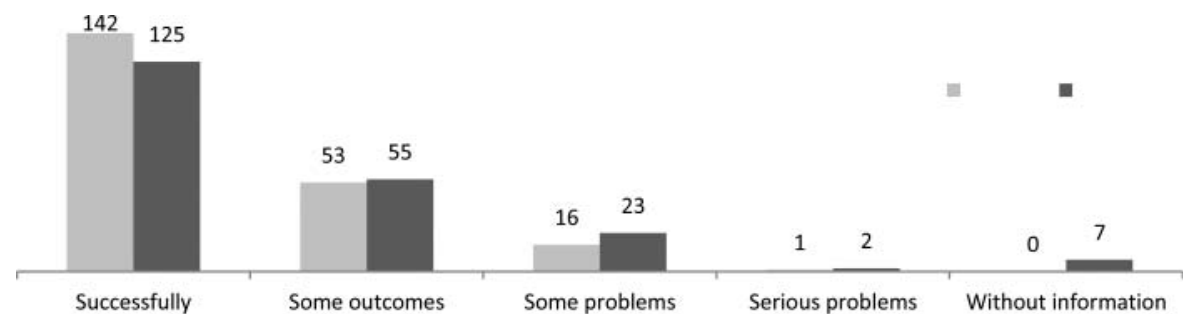

Figure 4. Foster care evaluation. 
found to contribute positively or negatively. Although foster care outcomes were, in the majority of the cases, classified as successful, the level of disagreement between foster carers and professionals was significant, with professionals being more positive and less critical with regard to placement success.

A divergence in the views of professionals and foster carers was also found regarding the occurrence of contact, and indicates the need to better understand what actually happens in practice. Improved monitoring will determine whether the data that professionals have is outdated, and will indicate if changes in the child's individual care plans are implemented in practice. This is important when there is absence of contact, even though it was authorized, but even more important when contact occurs when it was not expected or allowed. It is essential that professionals are provided with accurate information, as it contributes to the protection of children and young people and ensures their wellbeing. In this respect it is also important that both professionals and foster carers share the same definition of contact in order to avoid miscommunication or misinterpretation when events are assessed.

The apparent discrepancy between professionals' and foster carers' views may result from the fact that the knowledge of each of these groups is focused in certain areas: mostly logistical in the case of professionals, and mostly relational and emotional in the case of foster carers. Additionally, foster carers' emotional involvement must be monitored, because it may lead to difficulties with accepting the existence of contact between children and young people and their family. Foster carers may believe that by resisting contact they are protecting and promoting placement stability and the children and young people's wellbeing. The need for initial and continuous training of foster carers should be stressed, at least during the placement's initial phase, and while reunification is still a possible outcome, so it is made clear that they have the role of caring for children temporarily, while the biological family builds up and/or restores the conditions for family reunification.

Most foster carers in Portugal are poorly educated and/or have no training, which may explain their attitude of appropriation of the child, or at their least refusal to cooperate with or active creation of obstacles to contact. It is essential that policy makers promote initial training for new foster carers, and include the subject of contact in the training program, as well as ensure access to ongoing training for existing foster carers. Initial training should also be implemented immediately after the recruitment process, rather than after the approval to foster children and young people, as happens currently. Moreover, supervision should be particularly active in the initial phase of a placement, and professionals should monitor the placement closely. As discussed in the previous section, as placement length increases the possibility that the child or young person could to return to their biological family decreases. In fact, this study has found that children and young people who have contact with their family are typically younger, and that the longer children and young people stay in foster care, the greater the chance they have of losing contact with their family. The data in this study represents the most common type of foster care in Portugal: long term placement verging on quasi-adoption, which weakens or eliminates the bonds between the child or young person and their biological family. It can be discussed that, in accordance with the child's best interests, and when contact is not harmful, it is important to develop permanent connections with the biological family, and to promote positive contact, even when the reunification is not expected. By maintaining contact with the child, the biological family has the ability to ensure child's wellbeing and to participate in their development. This may contribute to a decrease in the resistance and mistrust typically associated with the decision to remove a child from their family and subsequent placement in foster care. It may also lead to better management of the emotional loss that results from the removal process, and to promoting a stronger identity structure in children and young people.

It is also necessary to adjust the management and organization of contacts so that professionals can systematically and effectively evaluate the associated reactions and their effects. This will not be possible at all if the number of cases that every professional has to monitor is too high. This concern is of extreme importance since professionals have a central role in the decision-making process for reunification, and in the cessation, maintenance, or change of contact arrangements.

Foster carers and professionals also have different perspectives on a child's reactions during and after visits, with professionals having a more positive attitude compared to that of foster carers. The perception 
of both groups is more positive regarding children and young people's reactions to visits, than their evaluation of foster care outcomes, indicating that contacts may have positive role in the children or young people lives, even if it does not have a positive impact on placement success. The differences between perspectives of professionals and foster carers shows that there is a certain distance or difficulty in communication between these two groups, which may interfere with placement evaluation and the child's individual care plan, particularly regarding the possibility of reunification with the child or young person's family. It is essential to bring these groups together and improve their communication, as they should work together as a team that shares the same goals. More contact time is needed between professionals and carers, more joint work meetings, more visits to the foster carers' homes, regular training sessions, discussion groups, and leisure activities. These are strategies that can contribute to improving communication and the sharing of knowledge about individual cases. Furthermore, some of these activities could include the children or young people and their biological families.

The difficulties reported by the different groups suggest the need for the continued involvement of professionals in contact in order to minimize or overcome logistical difficulties such as travel costs or distance between the residences of biological families and foster carers. As previously stated, this could be done by negotiating places and times that are favorable for both parties. It is also important to better understand the reasons that that give rise to biological families failing to follow contact agreements, and children and young people's being unwilling to participate in contact, as these lead to emotional and relational difficulties. Placements that are geographically closer to biological families and more accessible by various means of transportation facilitate the contact process but, given the shortage of foster carers available in the Portuguese child protection system, this goal will not be easy to achieve. On the other hand, the use of spaces for meetings that are functional, equally accessible to both parties, and considered neutral, i.e. not at the home of any of the parties, is a possible change that could increase the frequency and quality of contacts.

The use information and communication technologies, mentioned under other contacts in previous discussion, can have a significant role in this context, as it may contribute to the maintenance of contact and feelings closeness between the child or young person and their biological family. It is important to take into account that in modern society social networks are widely used by children and young people and constitute structural elements of children and young people's culture, which, if used carefully, can enhance contact (Almeida, Alves, \& Delicado, 2011).

\section{Conclusion}

As previously discussed, foster carers and professionals identified relational and emotional difficulties between children and young people in care and their families, pointing to need for more effective and continuous support for both parties, including training to improve the relational skills and management processes of biological families, in order to reduce these difficulties. The existence of contact cannot be dependent on the possibility of reunification of the child with their biological family. In fact, although it was found that contact does not appear to have any impact on the results of the placement, it should not be denied or hindered without well-founded reasons. This relationship between parents and children is important to the child's wellbeing. More specifically the involvement of biological families and experienced foster carers in policy development in the national context, could possibly contribute to the eradication of stereotypes promoting a cooperative relationship between all of the parties involved in the foster care process.

It is also important to point out some limitations of this study namely: the perspectives of biological families and children and young people were not included, the possible influence of social desirability on the answers of foster carers and professionals, and the restriction of data collection to only one area of the country. On the other hand, this study has several strengths, such as the significant sample size, which represents more than half of the total number of children and young people in care in the country; the originality of the investigation, because contact in foster care had never previously been studied in Portugal; and, the triangulation of sources, which allowed us to compare the perceptions of professionals and foster carers, and to detect, for the first time, discrepancies between the perceptions of reality of the two groups that need to be better studied and understood. 
In terms of implications for practice, the authors emphasize the need to gradually build a system of regulated cooperation that includes professionals and carers, especially in the planning and organization of contact. Ideally, they should all be part of a fostering team. This involvement can be achieved through the implementation of planning meetings, training, and meetings that promote the sharing of relevant information about the child in care. This system of sharing should be extended as far as is possible to the biological family, and should involve the child or young person as much as possible based on their age and maturity. The observed discrepancies in perception between foster carers and professionals reveal how professionals and carers assess and manage contact, which influences the maintenance and frequency of contact, and the continuity of the placement.

This study points to new research questions that should be developed in the future. For instance, how and why professionals and foster carers evaluate children and young people's reactions to the visits differently; what are the resources professionals need, and what is a reasonable amount of time required, to effectively support and evaluate a placement; and what do foster carers think and feel about the reunification of children and young people with their biological families. Finally, it is important to note that in addition to all these reflections, each placement is unique and has its own defining characteristics. For this reason, professionals need to work together with foster carers, children and young people in care and, whenever possible the biological family, in order to find the best possible arrangements and outcomes regarding contact on a case by case basis.

\section{References}

Aldgate, J., Maluccio, A., \& Reeves, C. (1989). Adolescents in foster families. Bradford on Avon: B.T. Batsford in Association with BAAF.

Almeida, A. N., Alves, N. A., \& Delicado, A. (2011). As crianças e a internet em Portugal. Perfis de uso. Sociologia, Problemas E Práticas, 65, 9-30.

Atwool, N. (2013). Birth family contact for children in care: How much? How often? Who with?. Child Care in Practice, 19(2), 181-198.

Barber, J., \& Delfabbro, P. (2004). Children in foster care. London: Routledge.

Beek, M., \& Schofield, G. (2004a). Providing a secure base in long-term foster care. London: BAAF.
Beek, M., \& Schofield, G. (2004b). Promoting security and managing risk: Contact in long-term foster care. In E. Neil \& D. Howe (Eds.), Contact in adoption and permanent foster care. Research, theory and practice (pp. 124-143). London: BAAF.

Biehal, N. (2006). Reuniting looked after children with their families. A review. London: National Children's Bureau.

Browne, D., \& Moloney, A. (2002). 'Contact irregular': A qualitative analysis of the impact of visiting patterns of natural parents on foster placements. Child and Family Social Work, 7(1), 35-45.

Cairns, K. (2002). Attachment, trauma and resilience: Therapeutic caring for children. London: BAAF.

Cantos, A., Gries, L., \& Slis, V. (1997). Behavioral correlates of parental visiting during family foster care. Child Welfare, 76 (2), 309-329.

Cleaver, H. (2000). Fostering family contact: A study of children, parents and foster carers. London: The Stationery Office.

Coakley, T. (2013). The influence of father involvement on child welfare permanency outcomes: A secondary data analysis. Children and Youth Services Review, 35(1), 174182.

David, M. (2000). Enfants, parents, famille d'accueil. Un dispositif de soins : l'accueil familial permanent. Ramonville Saint-Agne: Érès.

Delgado, P., López, M., Carvalho, J. M. S., \& Del Valle, J. (2015). Acolhimento familiar nos países do Sul da Europa. Uma investigação comparada sobre a satisfação dos acolhedores. Psicologia Reflexão \& Crítica, 28(4), 840-849.

Delfabbro, P., Barber, J., \& Cooper, L. (2002). The role of parental contact in substitute care. Journal of Social Service Research, 28(3), 19-39.

Déprez, A., \& Wendland, J. (2015). La visite parentale chez l'enfant placé, une revue de la littérature. Annales médicopsychologiques, 173 (6), 494-498.

Gilligan, R. (2000). The importance of listening to children in foster care. In G. Kelly, \& R. Gilligan (Eds.), Issues in foster care. Policy, practice and research (pp. 40-58). London: Jessica Kingsley.

Heptinstall, E., Bhopal, K., \& Brannen, J. (2001). Adjusting to a foster family. Children's perspectives. Adoption \& Fostering, 25(4), 6-16.

Howe, D. (1995). Attachment theory for social work practice. London: Macmillan Press.

Howe, D., Brandon, M., Hinings, D., \& Schofield, G. (1999). Attachment Theory, child maltreatment and family support. London: Macmillan Press.

Howe, D., \& Steele, M. (2004). Contact in cases in which children have been traumatically abused or neglected by their birth parents. In E. Neil \& D. Howe (eds.), Contact in adoption and permanent foster care (pp.203-223). London: British Association for Adoption \& Fostering.

Hunt, J., Waterhouse, S., \& Lutman, E. (2008). Keeping them in the family: Children placed in kinship care through care proceedings. London: BAAF. 
Instituto da Segurança Social. (2014). Casa 2013. Relatório de caracterização anual da situação de acolhimento das crianças e jovens. Lisboa: Instituto da Segurança Social.

McAuley, C. (1996). Children's perspectives on long-term care. In M. Hill \& J. Aldgate (Eds.), Child welfare services (pp. 170-179). London: Jessica Kingsley Publishers.

McWey, L., Acock, A., \& Porter, B. (2010). The impact of continued contact with biological parents upon the mental health of children in foster care. Children and Youth Services Review, 32(10), 1338-1345.

McWey, L., \& Mullis, A. (2004). Improving the lives of children in foster care: The impact of supervised visitation. Family Relations, 53(3), 293-300.

Moyers, S., Farmer, E., \& Lipscombe, J. (2006). Contact with family members and its impact on adolescents and their foster placements. British Journal of Social Work, 36(4), 541-559.

Neil, E., Beek, M., \& Schofield, G. (2003). Thinking about and managing contact in permanent placements: The differences and similarities between adoptive parents and foster carers. Journal of Clinical Child Psychology and Psychiatry, $8(3), 401-418$.

Neil, E., \& Howe, D. (2004). Contact in adoption and permanent foster care. London: BAAF.

Ofsted. (2009). Keeping in touch. A report of children's experience by the Children's Rights Director for England. Accessed at: http://www.ofsted.gov.uk/Ofsted-home/Publications-andre search/Browse-all-by/Care/Children-s-rights/Keepingintouch/(language)/eng-GB (accessed 18 January 2010).

Osborn, A., \& Delfabbro, P. (2009). Foster carers perceptions of the effects of parental contact upon children's psychosocial wellbeing in long-term foster care. Communities, Children and Families Australia, 4(2), 18-33.

Padbury, P., \& Frost, N. (2002). Solving problems in foster care. Key issues for young people, foster carers and social services. London: The Children's Society.

Palacios, J., \& Jiménez, J. (2007). Acogimiento familiar en Andalucía. Sevilla: Consejería para la Igualdad y Bienestar Social. Recuperado el 23 de septiembre de 2008 de: http:// www.juntadeandalucia.es/observatoriodelainfancia/OIA.

Salas, M. D., Fuentes, M. J., Bernedo, I. M., García, M. A., \& Camacho, S. (2009). Acogimiento en familia ajena y visitas de los menores con sus padres biológicos. Escritos de Psicología, 2(2), 35-42.

Salas, M. D., Fuentes, M. J., Bernedo, I. M., \& García, M. A. (2016). Contact visits between foster children and their birth family: the views of foster children, foster parents and social workers. Child \& Family Social Work, 21(4), 473-483.

Schofield, G., Beek, M., Sargent, K., \& Thoburn, J. (2000). Growing up in foster care. London: BAAF.
Schofield, G, \& Stevenson, O. (2009). Contact and relationships between fostered children and their families. In G. Schofield \& J. Simmonds (Eds.), The child placement handbook (pp.178-202). London: BAAF.

Selwyn, J. (2004). Placing older children in new families: Changing patterns of contact. In E. Neil \& D. Howe (Eds.), Contact in adoption and permanent foster care. Research, theory and practice (pp. 144-164). London: BAAF.

Sen, R., \& Broadhurst, K. (2011). Contact between children in out-of-home placements and their family and friends networks: A research review. Child and Family Social Work, 16 (3), 298-309.

Sen, R., \& McCormack, J. (2011). Foster carers' involvement in contact: Other professionals' views. Practice: Social Work in Action, 23(5), 279-292.

Sinclair, I. (2005). Fostering now. Messages from research. London: Jessica Kingsley Publishers.

Sinclair, I., Baker, C., Wilson, K, \& Gibbs, I. (2005). Foster children. Where they go and how they get on. London: Jessica Kingsley Publishers.

Sinclair, I., Gibbs, I., \& Wilson, K. (2004). Foster carers. Why they stay and why they leave. London: Jessica Kingsley Publishers.

Sinclair, I., Wilson, K., \& Gibbs, I. (2001). "A life more ordinary". What children want from foster placements. Adoption \& Fostering, 25(4), 17-26.

Théry, I. (1999). Les trois composantes de la filiation au temps du démariage. In Septièmes journées d'étude de l'Association nationale des placements familiaux (pp.119-131). Paris: L'Harmattan.

Triseliotis, J. (2010). Contact between looked after children and their parents: A level playing field. Adoption \& Fostering, 34 (3), 59-66.

United Nations. (1989). Convention on the rights of the child. New York: United Nations.

Vanschoonlandt, F., Vanderfaeillie, J., Van Holen, F., De Maeyer, S., \& Andries, C. (2012). Kinship and non-kinship foster care: Differences in contact with parents and foster child's mental health problems. Children and Youth Services Review, 34(8), 1533-1539.

Ward, H., Munro, E., \& Dearden, C. (2006). Babies and young children in care. Life pathways, decision-making and practice. London: Jessica Kingsley Publishers.

Whiting, J., \& Lee, R. (2003). Voices from the system: A qualitative study of foster children's stories. Family Relations, 52 (3), 288-295.

Wilson, K., \& Sinclair, I. (2004). Contact in foster care: some dilemmas and opportunities. In E. Neil \& D. Howe (Eds). Contact in adoption and permanent foster care (pp. 165183). London: BAAF. 